germination of dormant spores. Radiation may possibly have damaged the microvasculature in the area of the plate by electron scatter.

Postmortem studies showed radiation-induced pneumonitis. Sufficient reduction in the oxygen tension may have occurred to prejudice oxygenation of the tissues around the plate before clinical hypoxia was recognised. Prolonged immunosuppression is seen after bone-marrow transplantation, and cyclosporin A may have prevented an immune response by donor lymphocytes.

With the increasing use of highly immunosuppressive regimens for allogeneic and autologous marrow transplantation we suggest that such complications may be seen more frequently. In retrospect, careful attention to the patient's history and the use of prophylactic penicillin and passive immunisation might have been beneficial.

JRK is supported by the Leukaemia Research Fund. Miss S E Davies typed the manuscript.

1 Mason TE, Demaree RS, Margolis CI. Granulocytic sarcoma (chloroma), two years preceding myelogenous leukemia. Cancer 1973;31:423-31.

2 Barrett AJ, Kendra JR, Lucas C, et al. Cyclosporin A as prophylaxis against graft versus host disease in 36 patients. $\mathrm{Br}$ Med $\mathcal{f} 1982 ; 285: 162-6$. 3 Anonymous. Diagnosis of tetanus. (Editorial.) Lancet 1980;i:1066.

(Accepted 2 September 1982)

Department of Haematology, Westminster Medical School, London SW1P 2AP

J R KENDRA, MRCP, MRCPATH, research lecturer

O HALIL, MD, DPATH, registrar

A J BARRETT, MD, MRCPATH, senior lecturer

Department of Medical Microbiology, Westminster Medical School S SELWYN, MD, FRCPATH, professor

\section{Recurrent hyperinfestation with Strongyloides stercoralis in a renal allograft recipient}

A renal allograft recipient who became hyperinfested with Strongyloides stercoralis after unsuccessful live donor transplantation had a fatal recurrent hyperinfestation after subsequent cadaveric transplantation despite repeated courses of treatment with thiabendazole. Indiscriminate prophylaxis with thiabendazole of transplant recipients from endemic areas may therefore be ineffective and undesirable.

\section{Case report}

A 45-year-old Iranian man had a severe rejection one month after live donor renal transplantation. He was treated vigorously with methylprednisolone ( $1 \mathrm{~g}$ intravenously on three successive days), an increase in his dose of oral prednisolone (to $150 \mathrm{mg}$ initially reducing to $50 \mathrm{mg}$ over six days), and the addition of cyclophosphamide $25 \mathrm{mg}$ daily to his immunosuppressive regimen of azathioprine and prednisolone. The rejection was contained, but three weeks later he presented with fever, rigors, and prostration, which suggested a Gram-negative septicaemia. Intravenous fluid replacement and broad spectrum antibiotics, however, failed to improve his condition. He remained ill until hyperinfestation with $S$ stercoralis was diagnosed when rhabditiform larvae of the nematode were identified in his urine and stools. The only previous evidence of infestation was a transient eosinophilia of $26 \%$ on one occasion before transplantation.

Two three-day courses of thiabendazole $1.5 \mathrm{~g}$ twice daily were needed before the parasite was eradicated from the stool. The pyrexia persisted until Streptococcus faecalis was isolated from blood culture and treated appropriately.

The transplanted kidney failed over the succeeding four months and he was returned to intermittent haemodialysis. Repeated stool examinations failed to show persistence of the worm and there was no eosinophilia. Sixteen months after the first transplant he was given a second graft from a cadaveric donor. $S$ stercoralis was again identified in the stool postoperatively but was eradicated by a further three-day course of thiabendazole $1.5 \mathrm{~g}$ twice daily.

The transplanted kidney functioned well but six weeks later he returned with a troublesome dry cough and profound malaise. Physical examination and chest $x$-ray films initially showed no abnormality but the illness progressed catastrophically over a few hours with the onset of severe dyspnoea and diffuse abdominal tenderness. A repeat chest $x$-ray film then showed patchy bilateral opacification. Soon afterwards he had a cardiorespiratory arrest. He was resuscitated and ventilated but then developed copious frothy haemoptysis and died.

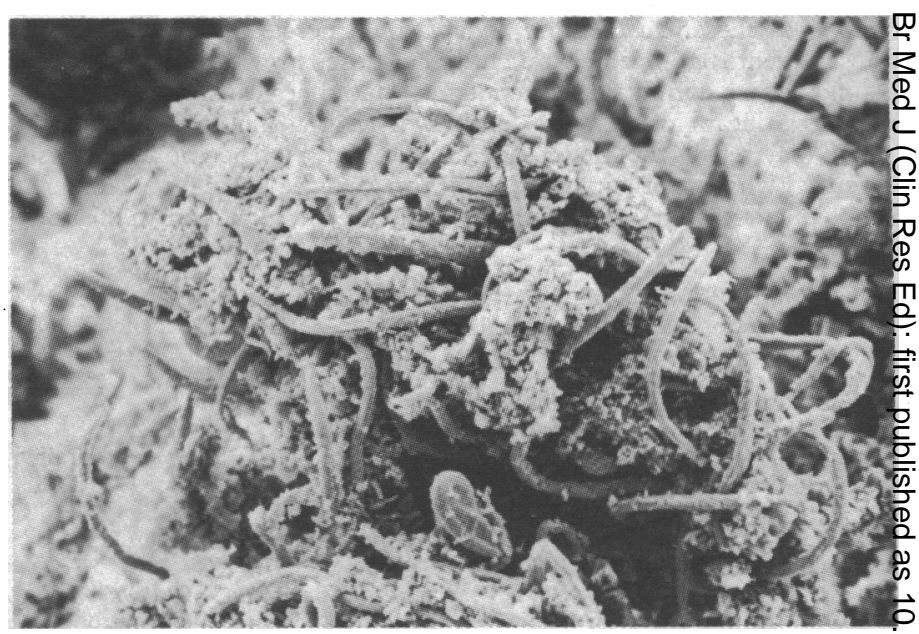

Scanning electron micrograph of filariform larvae on mucosal surface of duodenum ( $\times 321$ magnification).

Necropsy showed an extensive bilateral pneumonitis due to $S$ stercoralis with larval forms of the organism distributed throughout the body (figure)

\section{Comment}

Hyperinfestation with $S$ stercoralis may occur when a chronici duodenal carrier of the worm becomes debilitated or immunosuppressed.1 2 It is a well-recognised complication of renal trans-o plantation in patients who originate from warm climates where the nematode is endemic. ${ }^{3}$ It has been suggested that all such patientsw at risk should receive prophylactic treatment with thiabendazole."

This man developed fatal disseminated strongyloidiasis despite treatment with thiabendazole after a previous episode of hyper $-\frac{\mathbb{}}{3}$ infestation and again after the second transplant. Clearly, in theo conventional doses used here the drug was not effective prophylaxis against the worm.

The use of higher doses or longer courses of thiabendazole forp prophylaxis increases the likelihood of adverse effects from thiabendazole. This risk does not seem justified when hyperinfestation aftero transplantation is uncommon even in patients from endemic areas this case is the only one in our experience of more than 200 such patients. We recommend that prophylaxis be reserved for those patients in whom there is preoperative evidence of carriage of the organism such as unexplained eosinophilia or a history of symptomatic infestation. In these patients prolonged and repeated courses of thiabendazole are clearly appropriate. After transplantation frequent stool examinations and a keen awareness of the likelihood of hyper infestation still give the best hope of early diagnosis and effective treatment.

Correspondence should be addressed to: Dr C G Fowler, Department of Nephrology and Transplantation, Royal Free Hospital, London NW3.

1 Rivera E, Maldonado N, Velez-Garcia E, Grillo AJ, Malaret G. Hyperinfestation syndrome with Strongyloides stercoralis. Ann Intern Med $\frac{\rho}{3}$ 1970;72:199-204.

2 Scowden EB, Schaffner W, Stone WJ. Overwhelming strongyloidiasis:은 an unappreciated opportunist infection. Medicine (Baltimore) 1978;57: N

${ }^{3}$ Scoggin $\mathrm{CH}$, Call NB. Acute respiratory failure due to disseminated $D$ strongyloides in a renal transplant recipient. Ann Intern Med 1977; $87: 456-8$.

Weller IVD, Copland P, Gabriel R. Strongyloides stercoralis infection in $\mathbb{O}$ renal transplant recipients. $\mathrm{Br} \mathrm{Med} \mathcal{F} 1981$;282:524.

(Accepted 2 September 1982)

Department of Nephrology and Transplantation, Royal Free⿻ Hospital, London NW3

C G FOWLER, MRCP, FRCS, Ronald Gerard research fellow C G FOWLER, MRCP, FRCS, Ronald Gerard research fellow
IAIN LINDSAY, MRCPATH, Wellcome research fellow, department of
pathology

JACKIE LEWIN, MIST, senior medical laboratory scientific officer, department of pathology

PAUL SWENY, MRCP, MD, senior lecturer

O N FERNANDO, FRCS, FRCS(ED), consultant surgeo

J F MOORHEAD, FRCP, director and consultant physician 